Hossam El-Beheiry MB BCh PhD FRCPC, Jarmila Kim MD, Brian Milne MD FRCPC, Ronald Seegobin BM BCh MRCP FFARCS FRCPC

\title{
Prophylaxis against the systemic hypotension induced by propofol during rapid-sequence intubation
}

The objective of this study was to determine the effectiveness of two prophylactic approaches against the anticipated hypotension induced by propofol during rapid-sequence intubation. Thirty-six male or female nonpremedicated ASA class I-II patients aged 21-60 yr undergoing elective outpatient surgery were included in the study. Patients were randomly allocated to receive pre-induction ephedrine sulphate $\left(70 \mu \mathrm{g} \cdot \mathrm{kg}^{-1}\right.$ iv), preinduction volume loading ( $12 \mathrm{ml} \cdot \mathrm{kg}^{-1}$ Ringer's lactate $)$ or no treatment. Rapid-sequence intubation with cricoid pressure was then performed with propofol $\left(2.5 \mathrm{mg} \cdot \mathrm{kg}^{-1}\right)$ and succinylcholine $\left(1.5 \mathrm{mg} \cdot \mathrm{kg}^{-1}\right.$ ). The lungs were subsequently ventilated with $0.25-0.5 \%$ isoflurane in a $2: 1 \mathrm{~N}_{2} \mathrm{O} / \mathrm{O}_{2}$ mixture. Vecuronium was given once neuromuscular function had recovered from the succinylcholine. Heart rate and systemic arterial blood pressure were measured non-invasively before induction, afier propofol administration and every minute for ten minutes after intubation. Pre-induction volume loading prevented the hypotension observed before surgical stimulation in control and ephedrine groups. Moreover, pre-induction volume loading was not associated with increases in heart rate after intubation as was ephedrine administration. The intubating conditions were excellent to satisfactory in most patients and the overall incidence of adverse events during induction was mainly due to pain during injection of propofol. The present study showed that preoperative volume loading is more efficacious than pre-

\section{Key words}

ANAESTHETICS, INTRAVENOUS: propofol; COMPLICATIONS: hypotension; INTUBATION, TRACHEAL: rapid sequence; SYMPATHOMIMETICS: ephedrine sulfate.

From the Department of Anaesthesia and Critical Care, Queen's University, Kingston, Ontario, Canada.

Presented in part at the Canadian Anaesthetist's Society meeting, Edmonton, Alberta, June 1994.

Address correspondence to: Dr. Hossam El-Beheiry, Department of Anaesthesia, St. Michael's Hospital, 30 Bond Street, Toronto, Ontario, Canada M5B 1 W8.

Accepted for publication 24th May, 1995. induction administration of ephedrine sulphate in maintaining haemodynamic stability during rapid-sequence induction with propofol and succinylcholine. In addition, propofol in combination with succinylcholine provides excellent conditions for rapid-sequence intubation.

Cette étude a pour objet de déterminer l'efficacité de deux approches visant à prévenir lhypotension induite par le propofol pendant lïnduction en séquence rapide. Trente-six patients des deux sexes non prémédiqués de classe ASA I et II âgés de 21 à 60 ans programmés en chirurgie ambulatoire font partie de létude. Les patients sont répartis au hasard pour recevoir du sulfate d'éphédrine $\left(70 \mu \mathrm{g} \cdot \mathrm{kg}^{-1}\right.$ iv) avec une charge liquidienne (12 $\mathrm{ml} \cdot \mathrm{kg}^{-1}$ de lactate de Ringer) ou aucun traitement. Lintubation en séquence rapide avec pression cricoïdienne est exécutée sous propofol $\left(2,5 \mathrm{mg} \cdot \mathrm{kg}^{-1}\right)$ et succinylcholine $(1,5$ $\mathrm{mg} \cdot \mathrm{kg}^{-1}$ ). La ventilation mécanique est ensuite initiée avec de l'isoflurane 0.25 à $0,5 \%$ dans une mélange $\mathrm{N}_{2} \mathrm{O}_{2} \mathrm{O}_{2} \quad 2: 1$. Du vécuronium est administré après récupération de la succinylcholine. La fréquence cardiaque et la pression artérielle systémique sont mesurées avant l'induction et à toutes les minutes pendant dix minutes. La charge liquidienne préinduction prévient lhypotension observée avant la stimulation chirurgicale dans les groupes contrôles et éphédrine. En outre, la charge liquidienne préinduction n'est pas associée à une augmentation de la fréquence cardiaque après lintubation comme l'est l'éphédrine. Les conditions dintubation sont excellentes dans la plupart des cas et les complications se limitent presque totalement à de la douleur au moment de linjection du propofol. La présente étude montre que la charge liquidienne préinduction est plus efficace que l'administration de sulfate d'éphédrine pour maintenir la stabilité hémodynamique pendant linduction à séquence rapide avec le propofol et la succinylcholine. D'ailleurs, l'association de propofol et de succinylcholine procure d'excellentes conditions pour l'intubation en séquence rapide.

Rapid-sequence induction of anaesthesia is a challenging situation for the anaesthetist. The major considerations are rapid protection of the airway by a cuffed endo- 
tracheal tube, prevention of laryngospasm, regurgitation, vomiting and aspiration and maintenance of haemodynamic stability. The use of propofol may have several potential advantages that can achieve the major objectives of a rapid-sequence intubation technique. Propofol provides fast onset of action, ' potent attenuation of pharyngeal, laryngeal and tracheal reflexes ${ }^{2}$ and adequate depth of anaesthesia during intubation. ${ }^{1,3}$ However, a major disadvantage of rapid propofol bolus induction is the considerable decrement in systemic arterial blood pressure. ${ }^{4,5}$

This report determines the efficacy of two prophylactic approaches against the anticipated propofol-induced hypotension. The report also evaluates the use of propofol as the sole hypnotic agent during rapid-sequence intubation.

\section{Methods}

The study was approved by the Human Research Ethics Board of Queen's University. Thirty-six male or female unpremedicated ASA physical status 1 or 2 patients aged 21-60 yr were included in the study after they signed an informed consent. All patients were scheduled to undergo ambulatory surgery in whom rapid-sequence induction was not absolutely indicated. Surgical procedures performed were pelvic laparoscopy, arthroscopy and hand surgery. The exclusion criteria were a history of (1) allergy to the study medications; (2) uncontrolled cardiovascular, respiratory, hepatic or renal disease; (3) controlled or uncontrolled hypertension; (4) therapy with diuretics or vasoactive medications and (5) morbid obesity and pregnancy. Patients included in the study were allocated randomly into three groups: patients assigned to Group I did not receive any pretreatment before induction while those in Group II received ephedrine sulphate (70 $\left.\mu \mathrm{g} \cdot \mathrm{kg}^{-1} \dot{w}\right)$ just before induction of anaesthesia. Patients in Group III were volume loaded with Ringer's lactate $\left(12 \mathrm{ml} \cdot \mathrm{kg}^{-1}\right)$ over the $10-15 \mathrm{~min}$ before the administration of propofol. After pre-oxygenation for three minutes and pre-curarization with d-tubocurarine $3 \mathrm{mg} \dot{n}$, propofol $2.5 \mathrm{mg} \cdot \mathrm{kg}^{-1}$ bolus without lidocaine was administered in $<10 \mathrm{sec}$ and followed immediately by cricoid pressure and succinylcholine $\left(1.5 \mathrm{mg} \cdot \mathrm{kg}^{-1} i v\right)$. Laryngoscopy, orotracheal intubation and cuff inflation were carried out $30 \mathrm{sec}$ later. After confirming the position of the endotracheal tube, positive-pressure ventilation was started with the administration of $0.25-0.5 \%$ isoflurane in a 2:1 $\mathrm{N}_{2} \mathrm{O} / \mathrm{O}_{2}$ gaseous mixture. Vecuronium, $0.06 \mathrm{mg} \cdot \mathrm{kg}^{-1}$, was given once neuromuscular function had recovered from succinylcholine.

Preoperative baseline values of heart rate and blood pressure were the average of two consecutive readings at least ten minutes apart recorded in the Outpatient De-
TABLE I Grading of intubating conditions ${ }^{6}$

\begin{tabular}{ll}
\hline Grade & Criteria \\
\hline Excellent & $\begin{array}{c}\text { Good jaw relaxation, vocal cords open, no response to } \\
\text { intubation }\end{array}$ \\
Satisfactory & $\begin{array}{c}\text { Good jaw relaxation, vocal cords open, minimal } \\
\text { reaction to intubation }\end{array}$ \\
Fair & $\begin{array}{l}\text { Jaw relaxed, cords moving, intubation requiring firm } \\
\text { pressure and accompanied by moderate bucking or } \\
\text { coughing } \\
\text { Poor }\end{array}$ \\
\hline
\end{tabular}

partment. During the perioperative period, the heart rate and blood pressure were measured just before induction, after the administration of propofol and every minute for ten minutes after intubation using an automatic noninvasive blood pressure monitor. No surgical stimulation was performed until the first ten minutes after induction was completed to ensure no untoward extraneous effect on patients' physiological variables during the study period. Any complications during induction, i.e., somatic movements, vomiting, convulsions, larygospasm and coughing, were charted. Intubating conditions were classified as: excellent, satisfactory, fair and poor (Table I). ${ }^{6}$

Data are expressed as percentages of the baseline preoperative values (mean $\pm \mathrm{SD}$ ). Intragroup analysis was performed on raw data using one-way analysis of variance (ANOVA), followed by post-hoc Neuman-Keul's test for comparison with baseline. Comparison among groups was determined using two-way ANOVA for repeated measurements and the Mann-Whitney U-test. Differences were considered significant when $P<0.05$.

\section{Results}

Twenty women and 16 men were included in the study. The mean age and weight were $30 \pm 7.5 \mathrm{yr}$ and $77 \pm$ $12.5 \mathrm{~kg}$ for the control group, $29 \pm 6.7 \mathrm{yr}$ and $69 \pm$ $15.7 \mathrm{~kg}$ for the ephedrine group and $34 \pm 8.1 \mathrm{yr}$ and $72.6 \pm 14.5 \mathrm{~kg}$ for the volume loading group, respectively, and these were not significantly different. The difference among the three groups in male/female ratio, baseline systolic (SBP) and diastolic blood pressure and heart rate were not different. The SBP (mean \pm SD $\mathrm{mmHg}$ ) and the heart rate (mean \pm SD beats $/ \mathrm{min}$ ) in control, ephedrine and volume loading groups were $120 \pm 15.3$ and $82 \pm 22,126 \pm 17.9$ and $82 \pm 18$ and $122 \pm 19$ and $80 \pm 16$ respectively.

In the control group, the mean SBP just after propofol induction was $115 \pm 12.8 \mathrm{mmHg}(4.2 \pm 3 \%$ less than the mean preoperataive value). Immediately after intubation the SBP increased to $133 \pm 14.2 \mathrm{mmHg}$ and ten minutes later decreased to $82 \pm 9.2 \mathrm{mmHg}$ representing 


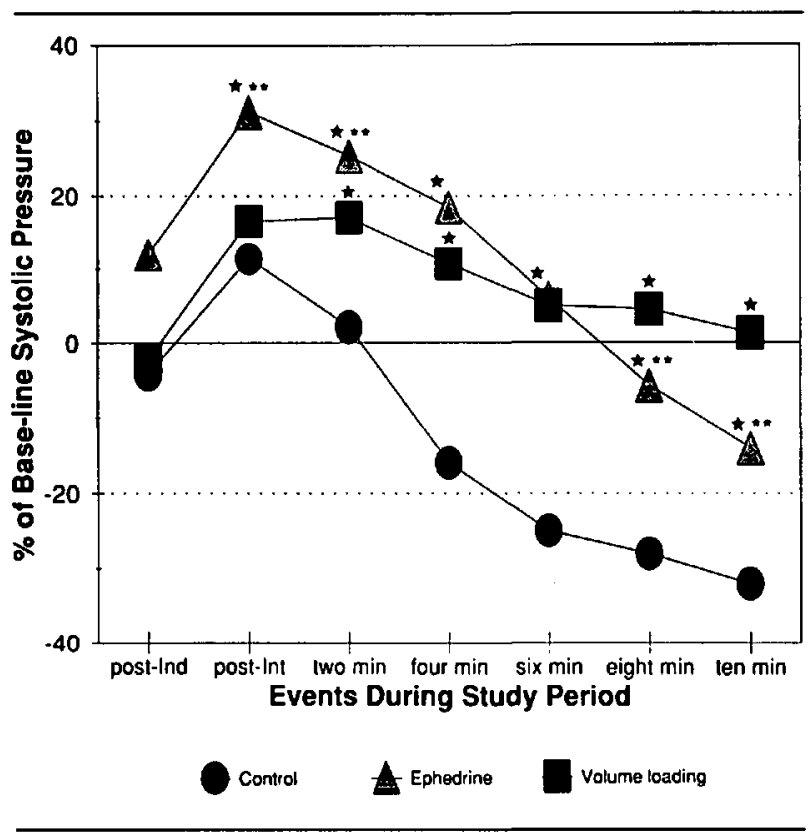

FIGURE 1 Mean changes in systolic arterial blood pressure during the study period in control, ephedrine and volume loading groups. Systolic pressure readings shown in the figure were recorded postinduction (post-ind), post-intubation (post-int) and every two minutes after intubation. $(\star)$ and $(\star \star)$ indicate statistical significance $(P<$ 0.05 ) from control and volume loading groups respectively.

$11.4 \pm 8.4 \%$ increase and $32.4 \pm 7 \%$ decrease from baseline (Figure 1). This pattern changed with pretreatment with ephedrine sulphate and with pre-induction loading with Ringer's lactate (Figure 1). In the ephedrine group there was an increase, rather than a decrease, in the postinduction SBP to $139 \pm 17 \mathrm{mmHg}$. The SBP reached a peak of $165 \pm 18.3 \mathrm{mmHg}$ just after intubation. However, ten minutes post-intubation the SBP was $108 \pm$ $10.7 \mathrm{mmHg}$, i.e., $14.1 \pm 8.7 \%$ less than baseline values. Pre-induction loading with Ringer's lactate did not increase the blood pressure postinduction as with ephedrine. Most importantly, volume loading prevented the delayed hypotension observed ten minutes after tracheal intubation in the control and ephedrine groups (Figure 1). The changes in the heart rate were statistically significant in the ephedrine group; post-induction, immediately postintubation, and ten minutes post-intubation heart rates were $108 \pm 10,122 \pm 9$ and $94 \pm 9$ beat $/ \mathrm{min}^{-1}$ respectively indicating an incrase from preoperataive values by $25.6,41.9$ and $10.6 \%$ (Figure 2). These changes were different from preoperative values and from the changes observed in control and volume loading groups.

The intubating conditions are shown in Table II. Intubations were graded as excellent and satisfactory in $94.4 \%$ of all the patients enrolled in the study without statistical difference between the groups. In two patients

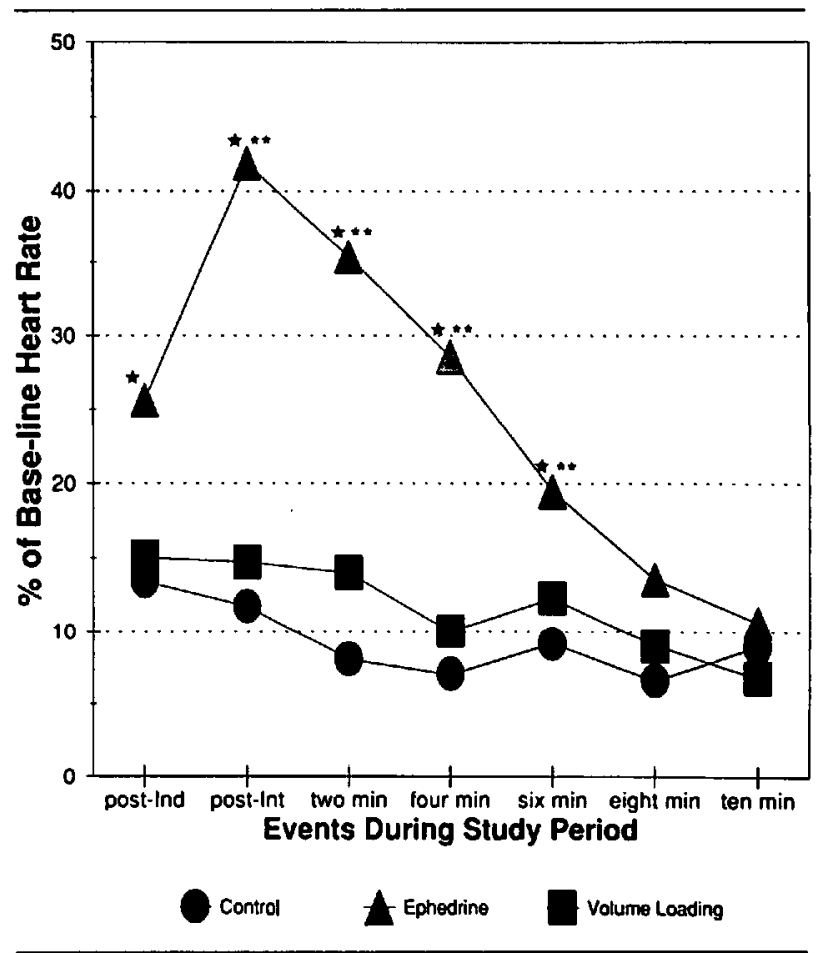

FIGURE 2 Mean changes in heart rate during the study period in control, ephedrine and volume loading groups. $(\star)$ and $(\star \star)$ indicate statistical significanoe $(P<0.05)$ from control and volume loading groups respectively.

TABLE II Grading of the intubating conditions during rapidsequence induction with propofol and succinylcholine

\begin{tabular}{llcl}
\hline Intubating conditions & $\begin{array}{l}\text { Control } \\
n=12\end{array}$ & $\begin{array}{l}\text { Ephedrine } \\
n=12\end{array}$ & $\begin{array}{l}\text { Volume loading } \\
n=12\end{array}$ \\
\hline Excellent & $9 / 12$ & $10 / 12$ & $8 / 12$ \\
Satisfactory & $2 / 12$ & $1 / 12$ & $4 / 12$ \\
Fair & $1 / 12$ & $1 / 12$ & $0 / 12$ \\
Poor & $0 / 12$ & $0 / 12$ & $0 / 12$ \\
\hline
\end{tabular}

the intubating conditons were graded as fair. The overall incidence of adverse events during induction with propofol was $19.4 \%$. Of these side effects, $11.1 \%$ were due to pain during injection. None of the complications prevented tracheal intubation. One patient in the ephedrine group had laryngospasm which was relieved after the administration of succinylcholine. During this incident the level of oxgyen saturation did not decrease below $96 \%$.

\section{Discussion}

This report evaluated the pre-induction use of $\dot{w}$ ephedrine sulphate or volume loading with Ringer's lactate as prophylactic measures against systemic hypotension induced by propofol induction during rapid-sequence in- 
tubation. These approaches have been previously used safely and studied extensively during the conduction of neuroaxial blocks ${ }^{8}$ and high-dose opioid induction of anaesthesia. ${ }^{9}$ The rationale for the prophylactic use of sympathomimetics or crystalloid loading is to attenuate the anticipated decrements in the systemic vascular resistance or to maintain the right ventricular filling pressure respectively.

In our investigations, the blood pressure response in the control group could be divided into three phases: postinduction decrease, post-intubation increase and a gradual decline reaching a peak ten minutes post-intubation (Figure 1). The slight initial reduction in SBP immediately after the propofol bolus is in disagreement with the 20-30\% reduction in SBP observed in previous investigations. 4,5 This may be due to the very short inductionintubation time, which is a necessary component of the rapid-sequence induction technique. The mean increase in the arterial systemic pressure after intubation represents the antagonism between the propofol-induced hypotension and the stress response to laryngoscopy and intubation. The mean peak decline in SBP by $\sim 30 \%$ ten minutes after intubation is mainly due to 2.5 $\mathrm{mg} \cdot \mathrm{kg}^{-1}$ propofol induction dose. However, a combination of other factors may have potentiated the observed hypotension, i.e., institution of positive-pressure ventilation and administration of isoflurane $0.25-0.5 \%$.

Administration of ephedrine sulphate immediately before induction produced modest post-induction hypertension, enhanced the post-intubation hypertension and failed to protect against the delayed hypotension observed in the control group (Figure 1). There also were considerable increases in the heart rates with a maximum mean of $41.9 \%$ just after intubation. On the other hand, pre-induction volume loading with Ringer's lactate abolished the post-induction decrease in SBP and the ten minute post-intubation hypotension (Figure 1). The slight heart rate increases in the volume loading group were not different from preoperative values or from those of the control group but were less than those from the ephedrine group (Figure 2). Therefore, pre-induction volume loading with Ringer's lactate provides more haemodynamic stability than the pre-induction administration of ephedrine sulphate $\dot{i}$ during rapid-sequence intubation.

There is little information about the use of propofol as the sole $i v$ hypnotic agent with succinylcholine during rapid-sequence induction. In a recent abstract, Merk and Goudsouzian ${ }^{10}$ compared the intubating conditions achieved with the use of propofol or thiopentone each in combination with atracurium or succinylcholine. In agreement with our observations, the intubating conditions were excellent to satisfactory in about $90 \%$ of the patients whose tracheas were intubated after induction with propofol and succinylcholine.

In conclusion, the use of propofol with succinylcholine during rapid-sequence induction of anaesthesia allowed rapid and smooth placement of the endotracheal tube without severe critical incidents. Preoperative ephedrine sulphate administration failed to prevent the delayed postintubation hypotension and led to excessive increases in the heart rate that may not be tolerated in high risk patients. On the other hand, preoperative volume loading with $12 \mathrm{ml} \cdot \mathrm{kg}^{-1}$ Ringer's lactate over $10-15 \mathrm{~min}$ successfully antagonised propofol-induced hypotension without increments in heart rate.

\section{References}

1 Doze VA, Westphal LM, White PF. Comparison of propofol with methohexital for outpatient anesthesia. Anesth Analg 1986; 65: 1189-95.

2 McKeating $K$, Bali $I M$, Dundee JW. The effects of thiopentone and propofol on upper airway integrity. Anaesthesia 1988; 43: 638-40.

3 Briggs LP, Dundee JW, Bahar M, Clarke RSJ.

Comparison of the effect of diisopropyl phenol (ICI 35 868) and thiopentone on response to somatic pain. $\mathrm{Br} \mathrm{J}$ Anaesth 1982; 54: 307-11.

4 Edelist $G$. A comparison of propofol and thiopentone as induction agents in outpatient surgery. Can $\mathbf{J}$ Anaesth 1987; 34: 110-6.

5 Hugg CC Jr, McLeskey CH, Narwold ML, et al. Hemodynamic effects of propofol: data from over 25,000 patients. Anesth Analg 1993; 77: S21-9.

6 Mirakhur RK, Shepherd WFI, Elliot P. Intraocular pressure changes during rapid sequence induction of anaesthesia: comparison of propofol and thiopentone in combination with vecuronium. Br J Anaesth 1988; 60: 379-83.

7 Zar J. Biostatistical Analysis, 2nd ed. New Jersey: Prentice Hall Inc., 1984: 138-80, 185-205.

8 Clark RB, Thompson DS, Thompson CH. Prevention of spinal hypotension associated with cesarean section. Anesthesiology 1976; 45: 670-4.

9 Lowenstein E, Hallowell P, Levine FH, Daggett WM, Austen WG, Laver $M B$. Cardiovascular response to large doses of intravenous morphine in man. $N$ Engl $J$ Med 1969; 281: 1389-93.

10 Merk HJ, Goudsouzain NG. Comparison of rapid intubating conditions with thiopental vs. propofol, succinylcholine vs timing technique with atracurium. Anesth Analg 1992; 74: S206. 